\title{
The microbiome in urological diseases
}

\author{
Kwang Woo Lee ${ }^{1}$ (D), Ho Yeon Song ${ }^{2}$ (D), Young Ho Kim ${ }^{1}$ \\ 'Department of Urology, Soonchunghyang University Bucheon Hospital, Soonchunghyang University College of Medicine, Bucheon, ${ }^{2}$ Department of Microbiology and \\ Immunology, Soonchunhyang University School of Medicine, Cheonan, Korea
}

Due to the rapid development of next-generation sequencing, it has become possible to obtain information on the sequences of all genes in a specific microbiome. The detection of bacteria in patients with no urinary tract infections indicated that the dogma that "urine is sterile" was false, leading to active research regarding the roles of the urinary microbiome in the human urinary tract. Here, we present a review of the current literature regarding the role of the microbiome in urology.

Keywords: Microbiota; Urine; Urologic diseases

This is an Open Access article distributed under the terms of the Creative Commons Attribution Non-Commercial License (http://creativecommons.org/licenses/by-nc/4.0) which permits unrestricted non-commercial use, distribution, and reproduction in any medium, provided the original work is properly cited.

\section{INTRODUCTION}

The term microbiome is a combination of "microbe," or "living in the body" and "biome," meaning ecosystem. The microbiome refers to the microorganisms living in the body and their genetic information, while the term microbiota refers to groups of microorganisms [1].

The human body is believed to contain 1.3 to 10 times as many microbes as human cells. Therefore, the human genome cannot be discussed without discussing microbes, which are sometimes referred to as a "second genome" [2].

Most bodily microorganisms are bacteria, but viruses, fungi, and protozoa are also found. The composition of the human microbiome varies between parts of the body, but a relatively balanced and stable community is maintained. There have been a number of investigations of the relationships of microorganisms with disease and metabolism. As recent studies have indicated that microbes have a significant impact on health, microbiomics has emerged as a growing research field in biology. Once the microbiome is completely interpreted as a map, the genes can be extracted from samples of blood, urine, stool, tissue, etc., and analyzed to predict, diagnose, and treat disease.

Identification of microorganisms is performed using the species specificity of $16 \mathrm{~S}$ rRNA. To do this, the microorganisms are first isolated and then mass-cultured and confirmed through the 16S rRNA of the cultured colonies. However, the types of microorganisms present in nature that can be purely cultured in medium are limited. To overcome these limitations, many attempts have been made to study microorganisms without relying on culture. Next-generation sequencing (NGS) has made it possible to obtain information about the entire sequence of genes in a particular microbial community.

Urine culture is still regarded as the gold standard for urinalysis; the diagnostic accuracy is excellent [3]. However, commonly used culture techniques do not detect slowly growing or anaerobic pathogens, such as Corynebacterium or Ureaplasma species. Given the developments in $16 \mathrm{~S}$ rRNA sequencing and enhanced quantitative urine culture (EQUC),

Received: 28 February, 2020 - Accepted: 20 May, 2020

Corresponding Author: Young Ho Kim (iD https://orcid.org/0000-0003-3959-0928

Department of Urology, Soonchunhyang University Bucheon Hospital, Soonchunhyang University College of Medicine, 170 Jomaru-ro, Wonmi-gu, Bucheon 14584 , Korea

TEL: +82-32-621-5463, FAX: +82-32-621-5018, E-mail: yhkuro@schmc.ac.kr 
abundant and diverse urinary microbiomes can be identified in every individual. EQUC can isolate up to $80 \%$ of all bacteria from samples that do not grow bacteria on standard urine culture [4-8]

The Human Microbiome Project (HMP) was started in 2007 to characterize the human microbiome and analyze its role in human health and disease. Initially, the project focused on the gastrointestinal tract, nasal cavity, mouth, skin, and the vagina, and did not include the urinary tract because the bladder and urine were considered to be sterile [911]. However, there is now evidence that the healthy urinary tract has a urinary microbiome, with age- and sex-specific genera, that changes in urological disorders. Therefore, there is growing interest in the role of the urinary microbiome [1214].

Here, we review the role of the microbiome in the field of urology, including studies of prostate cancer, bladder cancer, chronic prostatitis/chronic pelvic pain syndrome (CP/ CPPS), interstitial cystitis/bladder pain syndrome (IC/BPS), urgency urinary incontinence/overactive bladder (UUI/ $\mathrm{OAB}$ ), stone disease, and urinary tract infection (UTI) (Table 1) $[6,15-34]$.

\section{THE MICROBIOME AND UROLOGICAL CANCER}

Many infectious agents, which could act as cofactors in carcinogenesis, cause chronic inflammatory responses [35,36]. Certain commensal strains of bacteria may also control the outgrowth of pathogenic bacteria. This is consistent with other reports that the microbiome can control the immune response [37-39]. Therefore, the urinary microbiome may be involved in the regulation of pathogenic infection and cancer development.

\section{Prostate cancer}

Many pathogenic microorganisms are known to infect the prostate and induce symptomatic and asymptomatic inflammatory responses, including opportunistic endogenous Enterobacteriaceae, such as Escherichia coli and Pseudomonas spp., and sexually transmitted organisms (e.g., Neisseria gonorrhoeae, Chlamydia trachomatis, and Trichomonas vaginalis) $[40,41]$ Inflammation in the prostate plays an important role in the generation of prostate cancer, and cytokines such as interleukin ( $\amalg$ )- 6 and $\amalg-8$ have been reported to be involved in prostate cancer [42]. Some reports have also suggested that a history of sexually transmitted disease increases the likelihood of prostate cancer [43-45].

In the gut microbiota of prostate cancer patients, the level of Bacteroides massiliensis was found to be elevated and those of Faecalibacterium prausnitzii and Eubacterium rectale were reduced in the gut microbiota, compared with levels in healthy controls [15]. Bacteroides species possess $\beta$-glucuronidase genes that remove sugars when the glycated substrate in the liver reaches the large intestine. Increased circulating levels of sugar-free xenobiotics or mutagens are considered to cause prostate cancer [46]. In addition, $F$. prausnitzii and $E$. rectale produce butyrate using acetate. This is one of the most abundant short-chain fatty acids in the colon and has anti-inflammatory properties, suggesting that it is one of the pathways for preventing prostate cancer [15]. Liss et al. [16] reported that bacteria associated with carbohydrate metabolism are abundant, and those producing B-vitamins are lacking, in patients with prostate cancer, suggesting that micronutrients might play roles in the prevention of such cancer.

In addition to the gut microbiome, a number of studies on prostate tissue microbiomes have been reported. No significant differences were reported in the compositions of microbiomes between prostate cancer and benign tissues [17,18]. Cavarretta et al. [17] evaluated the microbiome profiles of tumor, peri-tumor, and nontumor tissue and reported that Propionibacterium spp. were the most abundant species. The high abundance of Propionibacterium spp., predominantly composed of Propionibacterium acnes, is consistent with the proinflammatory role of $P$. acnes and supports reports of its association with prostate cancer and reports that the level of staphylococci was higher, whereas that of streptococci was significantly lower, in tumor/peri-tumor tissue than in nontumor tissue. Feng et al. [18] analyzed tumor tissues and adjacent benign tissues using shotgun-based integrated metagenomic and metatranscriptomic analysis in radical prostatectomy specimens. Escherichia, Propionibacterium, Acinetobacter, and Pseudomonas were the most abundant genera. As Pseudomonas infection has a negative association with metastasis, it was suggested that Pseudomonas could serve as a biomarker for active surveillance. Any such association requires validation in a large-scale study, but further work on the prostate bacterial microbiome would facilitate diagnosis and inform treatment decisions.

\section{Bladder cancer}

Bacteria modulate cancer risks via both catabolism and anabolism of carcinogenic chemicals such as nitrosamine and acetaldehyde. It remains unclear whether the urinary microbiome affects the development or progression of bladder cancer, or whether bladder cancer affects the composition, diversity, and abundance of the urinary microbiome. 


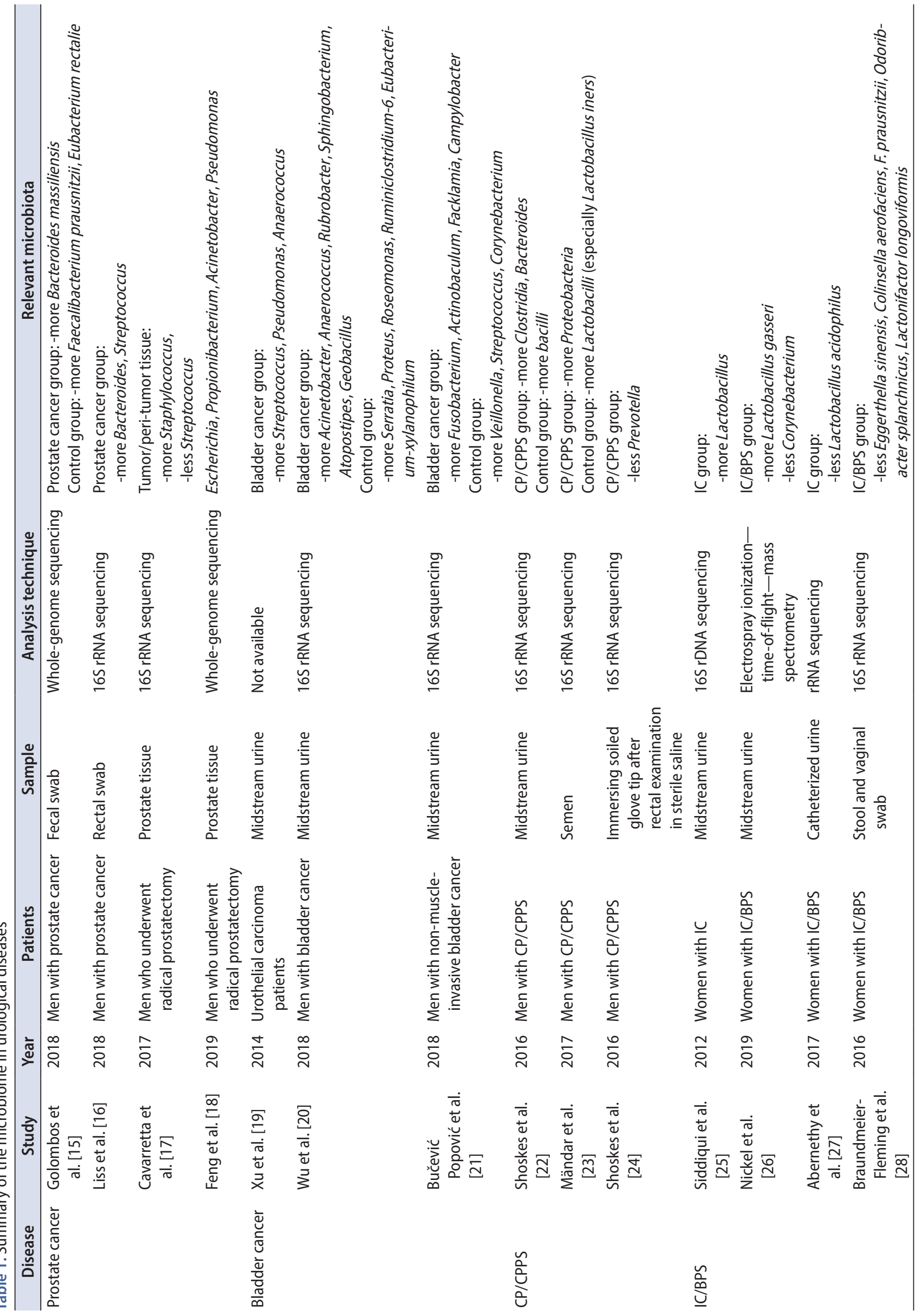




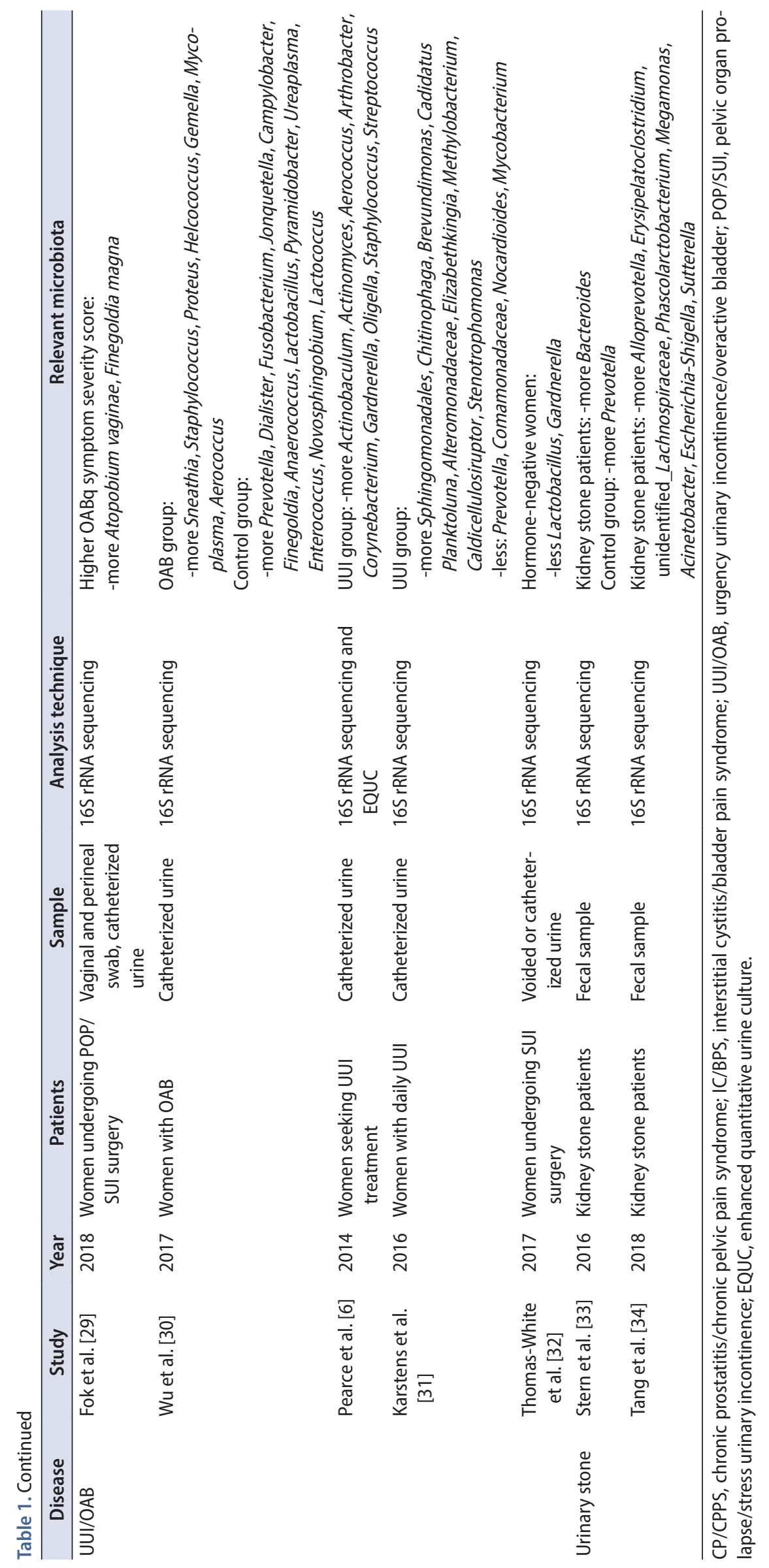


Some studies have suggested that the bladder microbiome may change the extracellular matrix (ECM) to promote or inhibit urothelial carcinogenesis [47] The ECM regulates tissue homeostasis and maintains the onset and progression of cancer, including bladder cancer [48,49].

Bacteria produce proteases that can act inside and outside of cells. These enzymes function as extracellular toxic factors that play an important role in host tissue degradation as well as evasion and destruction of host physical barriers. Among these factors, many bacterial enzymes capable of degrading ECM, including collagenases, elastases, and hyaluronidases, have been widely characterized [50-52]. In addition, bacterial invasion of tissues leads to inflammation, a reaction that further sustains ECM remodeling, and production of oxygen radicals, leading to mutations that cause DNA damage and both the development and recurrence of cancer [53].

There is a well-documented association between chronic Schistosoma haematobium bladder infection and bladder squamous cell carcinoma. However, the mechanism responsible for this association has not been clearly identified. Early studies suggested that bladder tumor development was caused by N-nitrosamines, polyaromatic hydrocarbons, free radicals, and microbes [54,55]. Adebayo et al. [56] investigated the urinary microbiomes of patients with urogenital schistosomiasis and found that certain urinary microbes including Fusobacterium, Sphingobacterium, and Enterococcus species (all of which are immunostimulatory) distinguished patients with urogenital schistosomiasis infections from healthy individuals. Of these microbes, Sphingobacterium and Aerococcus were considered to be potential markers of infection, and Trabulsiella and Weissella were considered to be markers of noninfection.

Bacille Calmette-Guérin (BCG, live attenuated Mycobacterium bovis) has long been used to treat urothelial bladder cancer. The mechanism by which the BCG vaccine prevents the recurrence and progression of bladder cancer remains poorly understood. However, BCG vaccine injection into the bladder induces inflammatory reactions that include antitumor immune responses [19,57].

Assuming that microbiota in the urinary tract could help to treat cancer if microorganisms are involved in the development and progression of cancer, it has been reported that oral administration of Lactobacillus casei reduces superficial bladder cancer recurrence [58,59]. L. casei prevents the production of carcinogens and mutagens by intestinal bacteria and the excretion of mutagens in urine [60]. L. casei modifies certain biological responses, enhancing activity of the human immune system [61].
In an animal study, intravesical instillation of the $L$. casei strain Shirota afforded a more potent response and was safer than BCG vaccine when used to treat superficial bladder tumors [62].

$\mathrm{Xu}$ et al. [19] reported that streptococci were enriched in urine from bladder cancer patients, although the study was preliminary in nature and thus had a small sample size. Wu et al. [20] analyzed midstream urine from 31 patients with bladder cancer and 18 controls; Acinetobacter, Anaerococcus, and Sphingobacterium species were abundant in bladder cancer patients. Herbaspirillum, Porphyrobacter, and Bacteroides species were detected in bladder cancer patients at high risk for recurrence and progression. However, another study found no significant differences in microbial diversity or the urinary microbiota between cancer patients and controls [21].

\section{The microbiome and CP/CPPS}

The cause of CP/CPPS in men has not yet been clearly identified. The diagnosis is made by exclusion of diseases that show similar symptoms, such as UTIs, cancer, and IC/ BPS with no anatomical abnormalities [63].

Several studies have compared the diversity of urine and intestinal microflora between CP/CPPS patients and controls. Shoskes et al. [22] analyzed the urinary microbiome in midstream urine from $25 \mathrm{CP} / \mathrm{CPPS}$ patients and 25 control subjects using 16S rRNA sequencing and found that bacterial diversity was higher in the CP/CPPS group than in the control group. Clostridia and Bacteroides species were over-represented, bacilli were under-represented, and the prevalence of anaerobic bacteria was significantly higher in the CP/CPPS group than in the controls. Mändar et al. [23] compared the seminal microbiome using 16S rRNA sequencing with semen from 21 CPPS patients and 46 control males. The species diversity was higher, and the numbers of lactobacilli (especially Lactobacillus iners) were lower, in the CPPS group.

CPPS is also known to be related to intestinal symptoms, which in turn are associated with gut dysbiosis [11]. Shoskes et al. [24] showed that gut microbiome diversity was low in $\mathrm{CP} / \mathrm{CPPS}$ patients, the distribution differed from that in the control group, and a decreased count of Prevotella with antiinflammatory effects may serve as a biomarker for identifying patients with CP/CPPS.

\section{The microbiome and IC/BPS}

IC/BPS is defined as suprapubic pain related to bladder filling, accompanied by other symptoms, such as increased daytime and night-time urination frequency, in the absence 
of proven urinary infection or other obvious causes. Therefore, diagnosis requires the exclusion of infection. However, high-throughput sequencing techniques for the characterization of microbiota in asymptomatic healthy controls and female IC patients show differences in urine composition between groups [25]. Reduced microbial diversity is evident in patients with IC, and the abundance of lactobacilli was significantly elevated in $90 \%$ of IC patients compared with $60 \%$ of controls. Another study showed low levels of Corynebacterium and high levels of Lactobacillus gasseri in the urine of BPS patients [26]. However, the above two studies used midstream urine samples, so the vaginal microbiome may have been contaminated. Abernethy et al. [27] reported that microbial diversity was decreased in catheterized urine samples, as in the above study, but Lactobacillus acidophilus was rather low.

The stool microbiome has also been studied for potential biomarkers and targeted therapies in patients with IC/BPS. One study showed that the level of some bacterial species, including Eggerthella sinensis, Colinsella aerofaciens, $F$. prausnitzii, Odoribacter splanchnicus, and Lactonifactor longoviformis, was reduced in stool samples from patients with BPS [28].

\section{The microbiome and UUI/OAB}

UUI is a disease that significantly affects the quality of life of patients, mainly women and the elderly, and may be a symptom of $\mathrm{OAB}$ or neurogenic detrusor hyperactivity. Many studies of the urinary microbiome have been conducted in patients with $\mathrm{OAB}$ and UUI, because OAB syndrome is frequently associated with UUI.

Fok et al. [29] reported that two bacterial species, Atopobium vaginae and Finegoldia magna, are associated with preoperative urinary symptom severity in women with stress urinary incontinence/pelvic organ prolapse and are thought to be factors affecting $\mathrm{OAB}$ symptoms. Wu et al. [30] reported that urinary microbiome diversity was lower in $\mathrm{OAB}$ patients than in healthy controls, and that decreases in bacterial diversity and richness were more severe in $\mathrm{OAB}$ patients with depression. In addition, some bacterial genera showed differences according to the presence of anxiety or depression in $\mathrm{OAB}$ patients, suggesting the presence of a brain-bladder-microbiome axis.

Research on the urinary microbiome, perturbation of which may cause functional disorders such as UUI, may help to optimize diagnosis and treatment. Several studies that have compared the urinary microbiomes of female UUI patients and healthy controls have reported significant differences in bacterial urine compositions and have reported that the dif- ferences affect symptom severity and treatment responses [6,7,31] Compared with controls, UUI patients exhibit higher Gardnerella and fewer Lactobacillus sequence profiles. Additionally, in culture tests using EQUC, nine genera (Actinobaculum, Actinomyces, Aerococcus, Arthrobacter, Corynebacterium, Gardnerella, Oligella, Staphylococcus, and Streptococcus) were more frequently found in samples from UUI patients [6]. Lactobacillus was isolated from both groups, but notably, L. gasseri was cultured more frequently from UUI urine and Lactobacillus crispatus more commonly from control urine.

Thomas-White et al. [32] reported that the urinary microbiome was more diverse in patients with a high body mass index and more UUI symptoms, and this diversity was associated with low levels of Lactobacillus in hormone-negative women (postmenopausal women not taking exogenous hormones). No correlation was evident between the urinary microbiome and stress urinary incontinence symptoms. In contrast, Karstens et al. [31] reported that UUI symptom severity was higher in patients with low microbial diversity. They attributed these contradictory results to the small numbers of patients, differences among those patients (primarily postmenopausal women not taking estrogen therapy), differences in urine sample volumes, and the different data preprocessing/filtering techniques used.

Because a high diversity in UUI patients correlates with the response to anticholinergic treatment, the response to oral UUI medication can be predicted if the urinary microbiome is analyzed. In one study, higher variety was associated with a reduced probability of a response to solifenacin; higher doses were needed by such patients [7]

This new view of the complex bacterial network underlying functional disorders, such as UUI, may help to optimize our understanding and treatment, but further research is needed to gain insight into the overall picture [64].

\section{The microbiome and stone disease}

The role of microorganisms in the formation of urinary stones is relatively well established. Urea-splitting organisms, such as Proteus mirabilis and Ureaplasma urealyticum, are known to raise urinary $\mathrm{pH}$, resulting in crystallization of calcium, magnesium, and phosphate in urine and leading to the formation of struvite stones known as infection stones.

The gut microbiome is a regulator of diet-driven metabolism, and gut dysbiosis is associated with metabolic diseases, such as diabetes, obesity, and cardiovascular disease. Diet is one of the most important factors for stone formation; it is important to consider the relationship between gut dysbiosis and urinary stone formation. Stern et al. [33] studied the differences and characteristics of gut microbiomes in patients 
with and without kidney stones. Kidney stone patients had higher levels of Bacteroides and less Prevotella than the control group. Tang et al. [34] recently analyzed the characteristics of gut microbiomes in kidney stone patients and found an abundance of proinflammatory bacteria and fewer anti-inflammatory bacteria in kidney stone patients than in healthy controls.

There have been a number of studies on the relationship between the generation of stones and Oxalobacter formigenes. Recent studies have demonstrated that $O$. formigenes reduces urinary oxalate by reducing intestinal absorption [65]. Some studies described $O$. formigenes as a probiotic with the potential to treat hyperoxaluria [66-69].

\section{The microbiome and UTI}

The microbiome is likely to play a role in UTIs as they are associated with bacteria. The pathogenesis of UTIs is often explained by the ascending of intestinal bacteria. Recent studies have reported the important roles of vaginal, urinary, and intestinal microbiota in the regulation of disease activity [70]. Commensal bacteria may surpass pathogens and act as barriers to uropathogens by releasing inhibitory or bactericidal molecules. A study of patients with indwelling urinary catheters suggested that microbial diversity plays a protective role in the development of UTIs and that UTIs can be caused by dysbiosis of commensals [71]

The most common treatment method for UTIs is antibacterial therapy. However, the use of broad-spectrum antibiotics may negatively affect beneficial bacterial populations of the host and, consequently, affect the selective growth of pathogenic bacteria. Prolonged use of antibiotics can cause unwanted side effects, such as bacterial resistance [72].

Lactobacilli can prevent the adherence, growth, and colonization of uropathogenic bacteria [73]. The antibacterial activity of Lactobacillus strains can be explained by acidification of mucosal surfaces, inhibition of adhesion of pathogens, production of substances, such as vitamins and immunomodulators, and synergistic activity with the host's immune system [74].

In the glycosaminoglycan layer of the vaginal epithelium, lactic acid excreted into the environment during carbohydrate metabolism reduces the $\mathrm{pH}$, creating a poor microenvironment for most pathogenic bacteria [75]. Lactobacillus species also produce antibacterial metabolites, including hydrogen peroxide and bacteriocin [76,77]. Because of this characteristic, studies have been conducted with Lactobacillus strains, and there are reports that Lactobacillus strains such as Lactobacillus rhamnosus GR-1, Lactobacillus fermentum RC-14, and Lactobacillus reuteri B-54 are effective for the treatment and prevention of UTIs [78-83]. However, the dose, duration, and routes of administration have not been established, and the evidence for efficacy is weak.

Fecal microbiota transplantation has been attempted to modulate the effects of the intestinal microbiota on the pathogenesis of recurrent UTIs. Tariq et al. [84] reported decreases in recurrent UTIs and the antibiotic-resistance profile of urinary bacteria in patients with recurrent Clostridium difficile infections during the year following fecal microbiota transplantation. In addition, recurrent UTIs were reported to have been treated by fecal microbiota transplantation in kidney transplant recipients [85]. Clinical trials of the safety and tolerability of urine transfusion in patients with recurrent UTIs have been conducted, but no results have been reported.

NGS can be used to identify causative pathogens in UTIs and to identify patterns of resistance to antibiotics [86,87]. Because it is clear that the urinary microbiome changes during UTI and antibiotherapy, efforts to prevent or treat recurrent UTIs by delivery of single strains into the bladder $[88,89]$ or vagina [83], or via fecal microbiota transplantation, will undoubtedly continue.

\section{CONCLUSIONS}

The observation that the urinary tract is not a sterile environment and has a complex and distinct urinary microbiome has led to a new perspective on urological diseases, which had heretofore been considered to have no microbiological etiology.

Consensus on terminology, specimen collection, storage techniques, and analytic approaches is necessary, and further large-scale studies are required. Once the urinary microbiome has been well characterized and a database to understand how these microorganisms are involved in human health and disease is completed, the microbiome will play many important roles in the diagnosis, treatment, prognosis, and prevention of urinary disease.

\section{CONFLICTS OF INTEREST}

The authors have nothing to disclose.

\section{AUTHORS' CONTRIBUTIONS}

Research conception and design: Young Ho Kim. Data acquisition: Kwang Woo Lee and Young Ho Kim. Data analysis and interpretation: Kwang Woo Lee. Drafting of the manuscript: Kwang Woo Lee. Critical revision of the manu- 
script: Ho Yeon Song and Young Ho Kim. Administrative, technical, or material support: Young Ho Kim. Supervision: Ho Yeon Song and Young Ho Kim. Approval of the final manuscript: all authors.

\section{REFERENCES}

1. Ursell LK, Metcalf JL, Parfrey LW, Knight R. Defining the human microbiome. Nutr Rev 2012;70(Suppl 1):S38-44.

2. Grice EA, Segre JA. The human microbiome: our second genome. Annu Rev Genomics Hum Genet 2012;13:151-70.

3. Bonkat G, Pickard R, Bartoletti R, Bruyere F, Geerlings SE, Wagenlehner F, et al. EAU guidelines on urological infections. Arnhem: European Association of Urology; 2017;34-5.

4. Whiteside SA, Razvi H, Dave S, Reid G, Burton JP. The microbiome of the urinary tract--a role beyond infection. Nat Rev Urol 2015;12:81-90.

5. Wolfe AJ, Toh E, Shibata N, Rong R, Kenton K, Fitzgerald M, et al. Evidence of uncultivated bacteria in the adult female bladder. J Clin Microbiol 2012;50:1376-83.

6. Pearce MM, Hilt EE, Rosenfeld AB, Zilliox MJ, Thomas-White $\mathrm{K}$, Fok C, et al. The female urinary microbiome: a comparison of women with and without urgency urinary incontinence. mBio 2014;5:e01283-14.

7. Thomas-White KJ, Hilt EE, Fok C, Pearce MM, Mueller $\mathrm{ER}, \mathrm{Kliethermes} \mathrm{S}$, et al. Incontinence medication response relates to the female urinary microbiota. Int Urogynecol J 2016;27:723-33.

8. Hilt EE, McKinley K, Pearce MM, Rosenfeld AB, Zilliox MJ, Mueller ER, et al. Urine is not sterile: use of enhanced urine culture techniques to detect resident bacterial flora in the adult female bladder. J Clin Microbiol 2014;52:871-6.

9. Human Microbiome Project Consortium. Structure, function and diversity of the healthy human microbiome. Nature 2012;486:207-14.

10. Human Microbiome Project Consortium. A framework for human microbiome research. Nature 2012;486:215-21.

11. Li JKM, Chiu PKF, Ng CF. The impact of microbiome in urological diseases: a systematic review. Int Urol Nephrol 2019;51:1677-97.

12. Lewis DA, Brown R, Williams J, White P, Jacobson SK, Marchesi JR, et al. The human urinary microbiome; bacterial DNA in voided urine of asymptomatic adults. Front Cell Infect Microbiol 2013;3:41.

13. Pearce MM, Zilliox MJ, Rosenfeld AB, Thomas-White KJ, Richter HE, Nager CW, et al. The female urinary microbiome in urgency urinary incontinence. Am J Obstet Gynecol 2015;213:347.e1-11.

14. Shrestha E, White JR, Yu SH, Kulac I, Ertunc O, De Marzo
$\mathrm{AM}$, et al. Profiling the urinary microbiome in men with positive versus negative biopsies for prostate cancer. J Urol 2018;199:161-71.

15. Golombos DM, Ayangbesan A, O'Malley P, Lewicki P, Barlow $\mathrm{L}$, Barbieri CE, et al. The role of gut microbiome in the pathogenesis of prostate cancer: a prospective, pilot study. Urology 2018;111:122-8.

16. Liss MA, White JR, Goros M, Gelfond J, Leach R, JohnsonPais T, et al. Metabolic biosynthesis pathways identified from fecal microbiome associated with prostate cancer. Eur Urol 2018;74:575-82.

17. Cavarretta I, Ferrarese R, Cazzaniga W, Saita D, Lucianò R, Ceresola ER, et al. The microbiome of the prostate tumor microenvironment. Eur Urol 2017;72:625-31.

18. Feng Y, Ramnarine VR, Bell R, Volik S, Davicioni E, Hayes $\mathrm{VM}$, et al. Metagenomic and metatranscriptomic analysis of human prostate microbiota from patients with prostate cancer. BMC Genomics 2019;20:146.

19. Xu W, Yang L, Lee P, Huang WC, Nossa C, Ma Y, et al. Minireview: perspective of the microbiome in the pathogenesis of urothelial carcinoma. Am J Clin Exp Urol 2014;2:57-61.

20. Wu P, Zhang G, Zhao J, Chen J, Chen Y, Huang W, et al. Profiling the urinary microbiota in male patients with bladder cancer in China. Front Cell Infect Microbiol 2018;8:167.

21. Bučević Popović V, Šitum M, Chow CT, Chan LS, Roje B, Terzić J. The urinary microbiome associated with bladder cancer. Sci Rep 2018;8:12157.

22. Shoskes DA, Altemus J, Polackwich AS, Tucky B, Wang H, Eng C. The urinary microbiome differs significantly between patients with chronic prostatitis/chronic pelvic pain syndrome and controls as well as between patients with different clinical phenotypes. Urology 2016;92:26-32.

23. Mändar R, Punab M, Korrovits P, Türk S, Ausmees K, Lapp E, et al. Seminal microbiome in men with and without prostatitis. Int J Urol 2017;24:211-6.

24. Shoskes DA, Wang H, Polackwich AS, Tucky B, Altemus J, Eng C. Analysis of gut microbiome reveals significant differences between men with chronic prostatitis/chronic pelvic pain syndrome and controls. J Urol 2016;196:435-41.

25. Siddiqui H, Lagesen K, Nederbragt AJ, Jeansson SL, Jakobsen KS. Alterations of microbiota in urine from women with interstitial cystitis. BMC Microbiol 2012;12:205.

26. Nickel JC, Stephens-Shields AJ, Landis JR, Mullins C, van Bokhoven A, Lucia MS, et al. A culture-independent analysis of the microbiota of female interstitial cystitis/bladder pain syndrome participants in the MAPP Research Network. J Clin Med 2019;8:415.

27. Abernethy MG, Rosenfeld A, White JR, Mueller MG, LewickyGaupp C, Kenton K. Urinary microbiome and cytokine 
levels in women with interstitial cystitis. Obstet Gynecol 2017;129:500-6.

28. Braundmeier-Fleming A, Russell NT, Yang W, Nas MY, Yaggie RE, Berry M, et al. Stool-based biomarkers of interstitial cystitis/bladder pain syndrome. Sci Rep 2016;6:26083.

29. Fok CS, Gao X, Lin H, Thomas-White KJ, Mueller ER, Wolfe AJ, et al. Urinary symptoms are associated with certain urinary microbes in urogynecologic surgical patients. Int Urogynecol J 2018;29:1765-71.

30. Wu P, Chen Y, Zhao J, Zhang G, Chen J, Wang J, et al. Urinary microbiome and psychological factors in women with overactive bladder. Front Cell Infect Microbiol 2017;7:488.

31. Karstens L, Asquith M, Davin S, Stauffer P, Fair D, Gregory WT, et al. Does the urinary microbiome play a role in urgency urinary incontinence and its severity? Front Cell Infect Microbiol 2016;6:78.

32. Thomas-White KJ, Kliethermes S, Rickey L, Lukacz ES, Richter HE, Moalli P, et al. Evaluation of the urinary microbiota of women with uncomplicated stress urinary incontinence. Am J Obstet Gynecol 2017;216:55.e1-55.e16.

33. Stern JM, Moazami S, Qiu Y, Kurland I, Chen Z, Agalliu I, et al. Evidence for a distinct gut microbiome in kidney stone formers compared to non-stone formers. Urolithiasis 2016;44:399407.

34. Tang R, Jiang Y, Tan A, Ye J, Xian X, Xie Y, et al. 16S rRNA gene sequencing reveals altered composition of gut microbiota in individuals with kidney stones. Urolithiasis 2018;46:503-14.

35. Burger M, Catto JW, Dalbagni G, Grossman HB, Herr H, Karakiewicz $\mathrm{P}$, et al. Epidemiology and risk factors of urothelial bladder cancer. Eur Urol 2013;63:234-41.

36. Sfanos KS, Yegnasubramanian S, Nelson WG, De Marzo AM. The inflammatory microenvironment and microbiome in prostate cancer development. Nat Rev Urol 2018;15:11-24.

37. Cho I, Blaser MJ. The human microbiome: at the interface of health and disease. Nat Rev Genet 2012;13:260-70.

38. Benson AK, Kelly SA, Legge R, Ma F, Low SJ, Kim J, et al. Individuality in gut microbiota composition is a complex polygenic trait shaped by multiple environmental and host genetic factors. Proc Natl Acad Sci U S A 2010;107:18933-8.

39. Markowski MC, Boorjian SA, Burton JP, Hahn NM, Ingersoll MA, Maleki Vareki S, et al. The microbiome and genitourinary cancer: a collaborative review. Eur Urol 2019;75:637-46.

40. Caini S, Gandini S, Dudas M, Bremer V, Severi E, Gherasim A. Sexually transmitted infections and prostate cancer risk: a systematic review and meta-analysis. Cancer Epidemiol 2014;38:329-38.

41. Yoon BI, Kim S, Han DS, Ha US, Lee SJ, Kim HW, et al. Acute bacterial prostatitis: how to prevent and manage chronic infection? J Infect Chemother 2012;18:444-50.
42. Puhr M, De Marzo A, Isaacs W, Lucia MS, Sfanos K, Yegnasubramanian $\mathrm{S}$, et al. Inflammation, microbiota, and prostate cancer. Eur Urol Focus 2016;2:374-82.

43. Hayes RB, Pottern LM, Strickler H, Rabkin C, Pope V, Swanson GM, et al. Sexual behaviour, STDs and risks for prostate cancer. Br J Cancer 2000;82:718-25.

44. Nelson DE, Van Der Pol B, Dong Q, Revanna KV, Fan B, Easwaran S, et al. Characteristic male urine microbiomes associate with asymptomatic sexually transmitted infection. PLoS One 2010;5:e14116.

45. Dong Q, Nelson DE, Toh E, Diao L, Gao X, Fortenberry JD, et al. The microbial communities in male first catch urine are highly similar to those in paired urethral swab specimens. PLoS One 2011;6:e19709.

46. Gill CI, Rowland IR. Diet and cancer: assessing the risk. Br J Nutr 2002;88 Suppl 1:S73-87.

47. Alfano M, Canducci F, Nebuloni M, Clementi M, Montorsi F, Salonia A. The interplay of extracellular matrix and microbiome in urothelial bladder cancer. Nat Rev Urol 2016;13:77-90.

48. Lu P, Weaver VM, Werb Z. The extracellular matrix: a dynamic niche in cancer progression. J Cell Biol 2012;196:395-406.

49. Berndt A, Richter P, Kosmehl H, Franz M. Tenascin-C and carcinoma cell invasion in oral and urinary bladder cancer. Cell Adh Migr 2015;9:105-11.

50. Vollmer P, Walev I, Rose-John S, Bhakdi S. Novel pathogenic mechanism of microbial metalloproteinases: liberation of membrane-anchored molecules in biologically active form exemplified by studies with the human interleukin- 6 receptor. Infect Immun 1996;64:3646-51.

51. Berka RM, Gray GL, Vasil ML. Studies of phospholipase C (heat-labile hemolysin) in Pseudomonas aeruginosa. Infect Immun 1981;34:1071-4.

52. Lyczak JB, Cannon CL, Pier GB. Establishment of Pseudomonas aeruginosa infection: lessons from a versatile opportunist. Microbes Infect 2000;2:1051-60.

53. Kiraly O, Gong G, Olipitz W, Muthupalani S, Engelward BP. Inflammation-induced cell proliferation potentiates DNA damage-induced mutations in vivo. PLoS Genet 2015;11:e1004901.

54. Zaghloul MS. Bladder cancer and schistosomiasis. J Egypt Natl Canc Inst 2012;24:151-9.

55. Mostafa MH, Sheweita SA, O'Connor PJ. Relationship between schistosomiasis and bladder cancer. Clin Microbiol Rev 1999;12:97-111.

56. Adebayo AS, Suryavanshi MV, Bhute S, Agunloye AM, Isokpehi RD, Anumudu CI, et al. The microbiome in urogenital schistosomiasis and induced bladder pathologies. PLoS Negl Trop Dis 2017;11:e0005826.

57. Redelman-Sidi G, Glickman MS, Bochner BH. The mechanism of action of BCG therapy for bladder cancer--a current 
perspective. Nat Rev Urol 2014;11:153-62.

58. Aso Y, Akazan H. Prophylactic effect of a Lactobacillus casei preparation on the recurrence of superficial bladder cancer. BLP Study Group. Urol Int 1992;49:125-9.

59. Naito S, Koga H, Yamaguchi A, Fujimoto N, Hasui Y, Kuramoto $\mathrm{H}$, et al. Prevention of recurrence with epirubicin and Lactobacillus casei after transurethral resection of bladder cancer. J Urol 2008;179:485-90.

60. Hayatsu H, Hayatsu T. Suppressing effect of Lactobacillus casei administration on the urinary mutagenicity arising from ingestion of fried ground beef in the human. Cancer Lett 1993;73:173-9.

61. Nagao F, Nakayama M, Muto T, Okumura K. Effects of a fermented milk drink containing Lactobacillus casei strain Shirota on the immune system in healthy human subjects. Biosci Biotechnol Biochem 2000;64:2706-8.

62. Takahashi T, Kushiro A, Nomoto K, Uchida K, Morotomi M, Yokokura T, et al. Antitumor effects of the intravesical instillation of heat killed cells of the Lactobacillus casei strain Shirota on the murine orthotopic bladder tumor MBT-2. J Urol 2001;166:2506-11.

63. Antunes-Lopes T, Vale L, Coelho AM, Silva C, Rieken M, Geavlete B, et al. The role of urinary microbiota in lower urinary tract dysfunction: a systematic review. Eur Urol Focus 2020;6:361-9.

64. Magistro G, Stief CG. The urinary tract microbiome: the answer to all our open questions? Eur Urol Focus 2019;5:36-8.

65. Siener R, Bangen U, Sidhu H, Hönow R, von Unruh G, Hesse A. The role of Oxalobacter formigenes colonization in calcium oxalate stone disease. Kidney Int 2013;83:1144-9.

66. Sidhu H, Allison MJ, Chow JM, Clark A, Peck AB. Rapid reversal of hyperoxaluria in a rat model after probiotic administration of Oxalobacter formigenes. J Urol 2001;166:1487-91.

67. Hoppe B, Beck B, Gatter N, von Unruh G, Tischer A, Hesse A, et al. Oxalobacter formigenes: a potential tool for the treatment of primary hyperoxaluria type 1. Kidney Int 2006;70:1305-11.

68. Hoppe B, Groothoff JW, Hulton SA, Cochat P, Niaudet P, Kemper MJ, et al. Efficacy and safety of Oxalobacter formigenes to reduce urinary oxalate in primary hyperoxaluria. Nephrol Dial Transplant 2011;26:3609-15.

69. Barnett C, Nazzal L, Goldfarb DS, Blaser MJ. The presence of Oxalobacter formigenes in the microbiome of healthy young adults. J Urol 2016;195:499-506.

70. Flores-Mireles AL, Walker JN, Caparon M, Hultgren SJ. Urinary tract infections: epidemiology, mechanisms of infection and treatment options. Nat Rev Microbiol 2015;13:269-84.

71. Horwitz D, McCue T, Mapes AC, Ajami NJ, Petrosino JF, Ramig RF, et al. Decreased microbiota diversity associated with urinary tract infection in a trial of bacterial interference. J
Infect 2015;71:358-67.

72. Stamm WE, Norrby SR. Urinary tract infections: disease panorama and challenges. J Infect Dis 2001;183 Suppl 1:S1-4.

73. Hanson L, VandeVusse L, Jermé M, Abad CL, Safdar N. Probiotics for treatment and prevention of urogenital infections in women: a systematic review. J Midwifery Womens Health 2016;61:339-55.

74. Iannitti T, Palmieri B. Therapeutical use of probiotic formulations in clinical practice. Clin Nutr 2010;29:701-25.

75. The scientific basis of urology. Ann R Coll Surg Engl 2001;83:370.

76. Aroutcheva A, Gariti D, Simon M, Shott S, Faro J, Simoes JA, et al. Defense factors of vaginal lactobacilli. Am J Obstet Gynecol 2001;185:375-9.

77. Barrons R, Tassone D. Use of Lactobacillus probiotics for bacterial genitourinary infections in women: a review. Clin Ther 2008;30:453-68.

78. Reid G, Bruce AW, Taylor M. Influence of three-day antimicrobial therapy and lactobacillus vaginal suppositories on recurrence of urinary tract infections. Clin Ther 1992;14:11-6.

79. Reid G, Bruce AW, Taylor M. Instillation of Lactobacillus and stimulation of indigenous organisms to prevent recurrence of urinary tract infections. Microecol Ther 1995;23:32-45.

80. Reid G, Bruce AW. Selection of Lactobacillus strains for urogenital probiotic applications. J Infect Dis 2001;183 Suppl 1:S77-80.

81. Dani C, Biadaioli R, Bertini G, Martelli E, Rubaltelli FF. Probiotics feeding in prevention of urinary tract infection, bacterial sepsis and necrotizing enterocolitis in preterm infants. A prospective double-blind study. Biol Neonate 2002;82:103-8.

82. Reid G, Charbonneau D, Erb J, Kochanowski B, Beuerman D, Poehner R, et al. Oral use of Lactobacillus rhamnosus GR-1 and L. fermentum RC-14 significantly alters vaginal flora: randomized, placebo-controlled trial in 64 healthy women. FEMS Immunol Med Microbiol 2003;35:131-4.

83. Reid G, Bruce AW. Probiotics to prevent urinary tract infections: the rationale and evidence. World J Urol 2006;24:28-32.

84. Tariq R, Pardi DS, Tosh PK, Walker RC, Razonable RR, Khanna S. Fecal microbiota transplantation for recurrent Clostridium difficile infection reduces recurrent urinary tract infection frequency. Clin Infect Dis 2017;65:1745-7.

85. Biehl LM, Cruz Aguilar R, Farowski F, Hahn W, Nowag A, Wisplinghoff $\mathrm{H}$, et al. Fecal microbiota transplantation in a kidney transplant recipient with recurrent urinary tract infection. Infection 2018;46:871-4.

86. McDonald M, Kameh D, Johnson ME, Johansen TEB, Albala D, Mouraviev V. A head-to-head comparative phase II study of standard urine culture and sensitivity versus DNA nextgeneration sequencing testing for urinary tract infections. Rev 
Urol 2017;19:213-20.

87. Mouraviev V, McDonald M. An implementation of next generation sequencing for prevention and diagnosis of urinary tract infection in urology. Can J Urol 2018;25:9349-56.

88. Darouiche RO, Green BG, Donovan WH, Chen D, Schwartz $\mathrm{M}$, Merritt J, et al. Multicenter randomized controlled trial of bacterial interference for prevention of urinary tract infection in patients with neurogenic bladder. Urology 2011;78:341-6.

89. Sundén F, Håkansson L, Ljunggren E, Wullt B. Escherichia coli 83972 bacteriuria protects against recurrent lower urinary tract infections in patients with incomplete bladder emptying. J Urol 2010;184:179-85. 